Acta Theriologica 38 (3): 297 - 304, 1993.

PL ISSN $0001-7051$

\title{
Evolutionary divergence of Microtus liechtensteini (Rodentia, Arvicolidae) based on the first lower molar
}

\author{
Patrick BRUNET-LECOMTE and Boris KRYŠTUFEK
}

\begin{abstract}
Brunet-Lecomte P. and Kryštufek B. 1993. Evolutionary divergence of Microtus liechtensteini (Rodentia, Arvicolidae) based on the first lower molar. Acta theriol. 38: $297-304$.

Morphometrical analysis of the first lower molar $\left(\mathrm{M}_{1}\right)$ confirmed Microtus liechtensteini (Wettstein, 1927) to be closer to $M$. multiplex than to $M$. subterraneus. In the terms of the inclination of the pitymyan rhombus, $M$. liechtensteini appeared to be more evolved than $M$. multiplex. Significant interpopulation variability was recorded as regards morphometrical analysis of $\mathrm{M}_{1}$ in $M$. liechtensteini: $M$. l. petrovi was larger than the nominate race $M$. l. liechtensteini, while populations from the sub-Mediterranean zone differed by more open anterior loop.

Laboratoire de Paléontologie analytique et Géologie sédimentaire (URA CNRS 157) et Laboratoire de Préhistoire et Paléoécologie du Quaternaire de l'EPHE, Centre des Sciences de la Terre, 6 Bd Gabriel, 21000 Dijon, France (PB-L); Slovene Museum of Natural History, Prešernova 20, P.O. Box 290, 61001 Ljubljana, Slovenia (BK)

Key words: rodents, arvicolids, morphometry, evolution, Slovenia, Croatia
\end{abstract}

\section{Introduction}

Microtus lichtensteini (Wettstein, 1927) was described on the base of a single specimen collected from the peak Mali Rajinac, $1699 \mathrm{~m}$ a.s.l. (Velebit Mts., northwestern part of the Dinaric Alps). Ellerman and Morrison-Scott (1951) considered this vole as a subspecies of Microtus subterraneus, while Djulić and Mirić (1967) treated it as a form of Microtus multiplex. Petrov and Živković (1971) found voles from the type locality of $M$. liechtensteini to have diploid number $2 n=46$ and the fundamental number of arms $\mathrm{NF}=52$. They were thus different from $M$. multiplex with the chromosomal set $2 \mathrm{n}=48$ and $\mathrm{NF}=54$ (Meylan 1970). Consequently, $M$. liechtensteini was regarded as an independent species. Its distribution area extends from southeastern Alps in Austria and Slovenia to the northwestern Dinaric Alps. Presumably isolated populations were reported from the southern margin of Pannonian plain in Croatia, from Bosnia, and from Mt Tara in western Serbia (Král et al. 1978, Petrov and Živković 1979, Tvrtković et al. 1979, Kryštufek 1984, Purger and Karanović 1991). Ground voles with the liechtensteini karyotype were reported also from the eastern part of the Italian Alps (Storch and Winking 1977). 
Near Calliano (North Italy) two hybrids with intermediate karyotype were found on the contact zone of $M$. multiplex and $M$. liechtensteini (Storch and Winking 1977). This gave reason to regard multiplex and liechtensteini as parapatric karyological forms of one species (Niethammer and Krapp 1982). Graf and Meylan (1980) who produced interfertile hybrids in captivity assumed that only one polytypic species occurs with distribution area extending from France to the Balkans. Such an opinion of the taxonomic position of $M$. liechtensteini is still not generaly accepted. While it is by some authorities as a chromosomal race of M. multiplex (Graf and Meylan 1980, Niethammer and Krapp 1982, Petrov 1992), others concern it as an independent species (Corbet 1978, Nowak 1991). According to available zoogeographical and karyological evidence it is clear that $M$. liechtensteini and M. multiplex are two parapatric biospecies of a superspecies. Therefore we cannot agree with Petrov (1992) who synonymized $M$. liechtensteini and $M$. multiplex on the base of the "broad species concept".

Intraspecific variation of $M$. liechtensteini was demonstrated among populations from Slovenia and Croatia. Živković et al. (1975) described geographic variation in the position of centromere on both heterochromosomes. Populations from the sub-Mediterranean part of this area are larger than the continental ones and were described as a new subspecies M. liechtensteini petrovi (Kryštufek 1983). The subspecies populates dry and warm sub-Mediterranean regions with scarce forests, while the nominate race lives mainly in continental beech and spruce forests, frequently in higher altitudes. M. l. petrovi is very little known form, and only few specimen were collected by snap traps. The majority of material was obtained from owl pellets, where its dominance may attain values up to $15 \%$ (Lipej 1988). The karyotype of $M$. l. petrovi has not been studied as yet.

Enamel pattern of the first lower molar $\left(\mathrm{M}_{1}\right)$ in $M$. liechtensteini is predominantly of the medio-European subterraneus-multiplex type characterized by a long anterior part and a closed anterior loop. In some populations the Mediterranean type of $\mathrm{M}_{1}$, with an open anterior loop and a short anterior part, has been also observed. However, such a rough approach towards the study of $\mathrm{M}_{1}$ enamel pattern cannot tell whether $M$. liechtensteini is closer to $M$. multiplex than to $M$. subterraneus in terms of $\mathrm{M}_{1}$ morphology, nor to analyse divergences among different populations. Morphometrical analysis of $M$. liechtensteini populations from different biogeographical regions, and comparison with $\mathrm{M}_{1}$ patterns of $M$. multiplex and $M$. subterraneus, was undertaken to answer these two questions.

\section{Material and method}

We examined 163 teeth of $M$. liechtensteini from 28 samples from Slovenia and Croatia ( 1 - Planica Valley, 2 teeth; 2 - Kobarid, 3 teeth; 3 - Mt Pokljuka, 1 tooth; 4 - Mt Jelovica, 4 teeth; 5 - Jezersko, 1 tooth; 6 - Kamniška Bistrica, 1 tooth; 7 - Vojsko, 2 teeth; 8 - Ajdovščina, 2 teeth; 9 - Nova Gorica, Vogrsko, 4 teeth; 10 - Ljubljana, Ig, 3 teeth; 11 - Mt Travna gora, 4 teeth; 12 - Sevnica, 1 tooth; 13 - Mokro polje, 1 tooth; 14 - Mt Snežnik, 8 teeth; 15 - Klivnik, 2 teeth; 16 - Mt Risnjak, 12 teeth; 
17 - Kubed, 20 teeth; 18 - Sočerga, 1 tooth; 19 - Stena, 2 teeth; 20 - Mirna 1, 30 teeth; 21 - Mirna 2, 30 teeth; 22 - Mirna 3, 11 teeth; 23 - Mt Učka, 11 teeth; 24 -Štirovača, Alan, 1 tooth; 25 - Zavižan, 2 teeth, 26 - Baške Oštarije, 1 tooth; 27 - Plitvice, 2 teeth; 28 - Mt Makljen, 1 tooth), and compared them with M. multiplex (166 teeth from: Col du Lautaret, Hautes-Alpes, France, 30 teeth; Col du Montgenèvre, Hautes-Alpes, France, 17 Teeth; Les Vigneaux, Hautes-Alpes, France, 10 teeth; La-Chapelle-en-Vercors, Drôme, France, 12 teeth; Saint-Martin-de-la-Cluze, Isère, France, 10 teeth; Zermatt, Wallis, Switzerland, 12 teeth; Gudo, Ticino, Switzerland, 12 teeth; Meride, Ticino, Switzerland, 10 teeth; Varenzo, Ticino, Switzerland, 11 teeth; Mazzolla, Toscana, Italy, 30 teeth; Fivizzano, Toscana, Italy, 12 teeth) and $M$. subterraneus (226 teeth from: Fougères, Ile-et-Vilaine, France, 30 teeth; Quetteville, Calvados, France, 29 teeth; Hostiaz, Ain, France, 30 teeth; La Roquille, Gironde, France, 24 teeth; Localities from Tarn, France, 11 teeth; Bussy, Loire, France, 30 teeth; Champéry, Valais, Switzerland, 22 teeth; Chavradura, Grisons, Switzerland, 10 teeth; Montricher, Vaud, Switzerland, 10 teeth; Niepołomice, Poland, 30 teeth).

The specimens of $M$. liechtensteini were assigned to 10 geographical samples (sample A = samples 17 and 18 ; sample $\mathrm{B}=$ samples 14,15 , and 16 ; sample $\mathrm{C}=$ samples $1,2,3$, and 4 ; sample $\mathrm{D}=$ sample 23; sample $\mathrm{E}=$ samples 7,8 , and 9 ; sample $\mathrm{F}=$ samples $24,25,26$, and 27 ; sample $\mathrm{G}=$ samples 10 and 11 ; sample $H=$ sample 20 ; sample $I=$ sample 21 ; sample $J=$ sample 22 ) for the analysis of morphometric variations within and between species (Fig. 1). Sample areas were kept as small as possible and selected so as to represent and integral geographic area. Samples A, H, I, and J were from the sub-Mediterranean zone as defined by Jovanović et al. (1986), and samples B to G from the continental zone. According to Sugar (1984), samples A and I were from the boundary between the two zones, but still in the sub-Mediterranean region. The samples $5,6,12,13,19$, and 28 were removed from the analysis because of the low number.

Affinities among the three taxa and among geographic samples of $M$. liechtensteini were assesed by the canonical discriminant analysis of 21 parameters measured on the $M_{1}$ (Fig. 2): measures 1 to 6 , measures 7 to 13 and measures 15 to 22 . The measures 14 and 23 were removed from the analysis because of the difficulty to take the measures in the worn teeth. Variations of total length of $\mathrm{M}_{1}$ (TL = measure 6 ), anterior part of $\mathrm{M}_{1}[\mathrm{AP}=($ measure 6 - measure 3$) /$ measure 6$]$, pitymyan rhombus $(\mathrm{PR}=$ measure 4 - measure 3$)$ and anterior loop $(\mathrm{AL}=$ measure 20 -measure 18$)$ among the three species and among $M$. liechtensteini geographic groups as defined by previous discriminant analysis were analysed by one-way analysis of variance completed by the Scheffé contrast method.

Fig. 1. Geographic distribution of samples of Microtus liechtensteini analysed in this study.

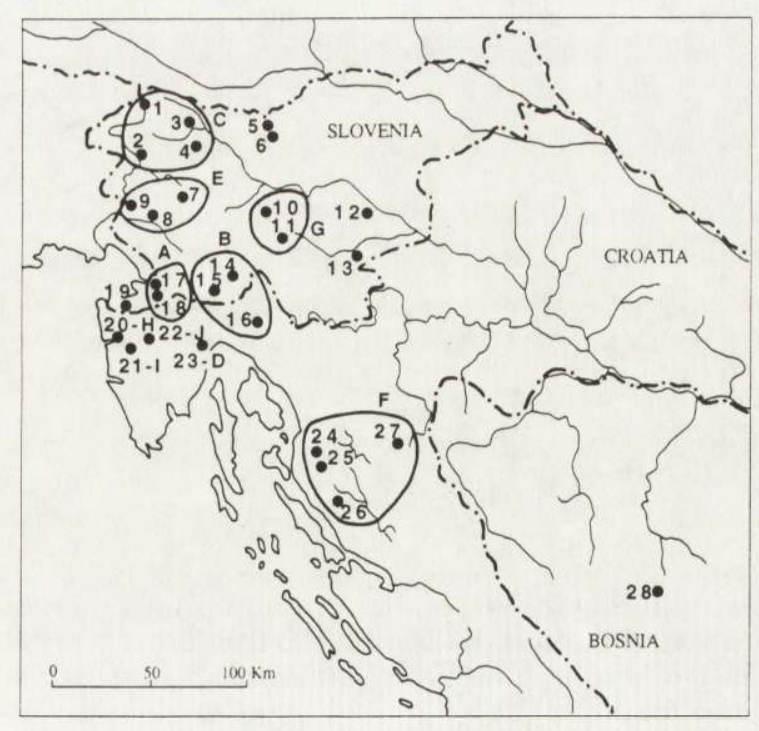



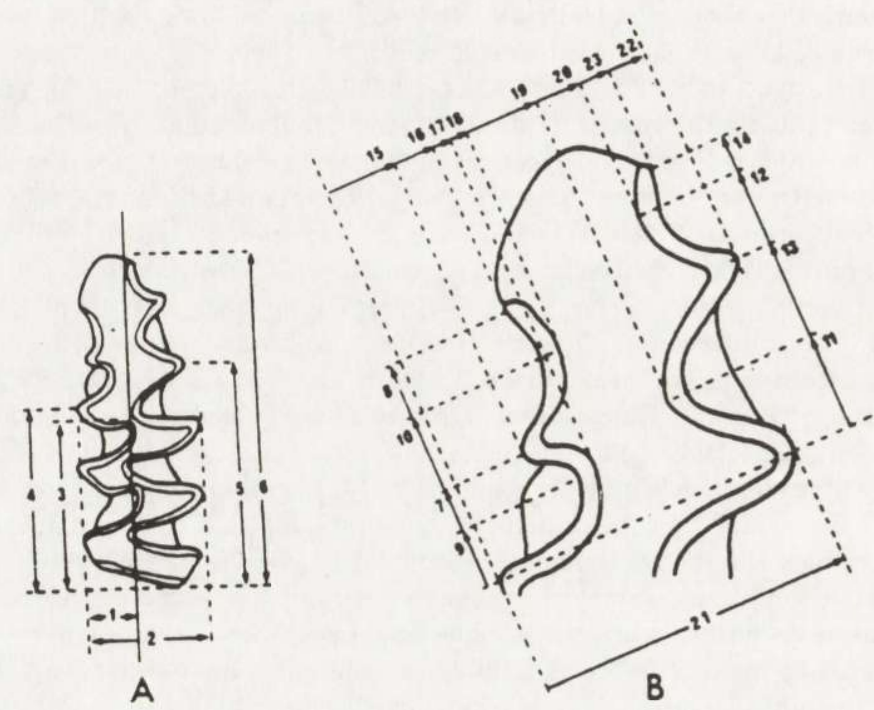

Fig. 2. Morphometry of the first lower molar. A - reference axis of the tooth and general measures. $\mathrm{B}-$ measures of the anterior complex.

\section{Results}

At first step the three species were subjected to the canonical discriminant analysis. The first two canonical axes explained $40 \%(p<0.001)$ and $14 \%$ $(p<0.001)$ of the variance between populations. The first canonical axis was significantly correlated $(p<0.05)$ with measure $2(0.84)$, measure $21(0.82)$, measure $22(0.79)$, measure $5(0.75)$, and measure $3(0.75)$. The second canonical axis had

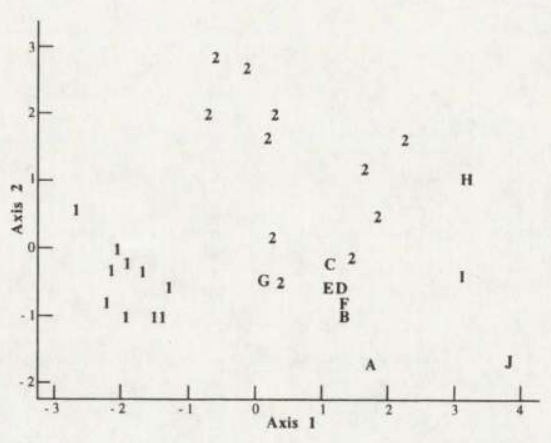

Fig. 3. Projection of centroids of the samples of Microtus liechtensteini (labels A to J), M. subterraneus (labels 1) and M. multiplex (labels 2) in the plan $1-2$ of interspecific canonical discriminant analysis.

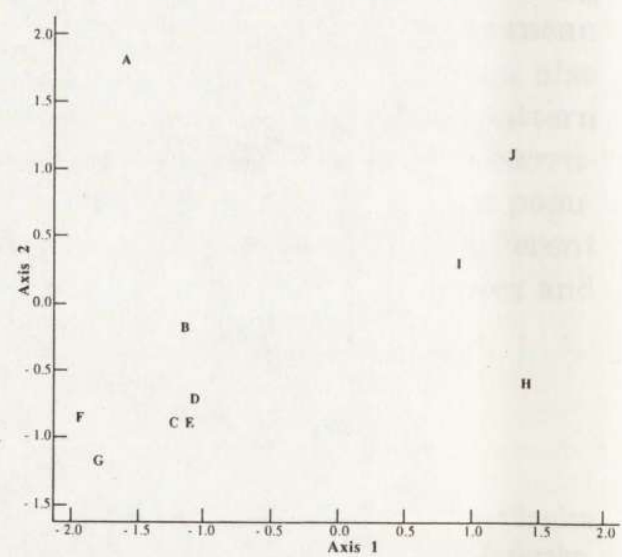

Fig. 4. Projection of centroids of the samples of Microtus liechtensteini (labels A to J) in the plan $1-2$ of intraspecific canonical discriminant analysis. 
significant negative correlations $(p<0.05)$ with measure $18(-0.48)$, measure 17 $(-0.35)$, and measure $22(-0.28)$. Populations belonging to $M$. subterraneus were clearly discriminated from other $M$. multiplex and $M$. liechtensteini populations on the first axis (Fig. 3), showing thereby that M. liechtensteini is morpohologically closer to $M$. multiplex than to $M$. subterraneus. As the first axis discriminated samples according to the size, $M$. subterraneus appeared to be the smallest of the species. The combination of the first two axes provided reasonably good discrimination between $M$. liechtensteini and $M$. multiplex samples. Second canonical axis was explained as shape vector. It is evident that size alone was not sufficient to discriminate $M$. liechtensteini from $M$. multiplex since they were of the same general size. Samples A, H, I, and J, all belonging to M. liechtensteini, were obviously quite appart from the remaining $M$. liechtensteini samples.

Morphometric characteristics of the $\mathrm{M}_{1}$ in three species are given in Table 1. The total length of the $\mathrm{M}_{1}$ is significantly different between the three species, $M$. liechtensteini having the greatest total length of the $\mathrm{M}_{1}$ and $M$. subterraneus the smallest. The anterior part is significantly shorter in $M$. multiplex than in $M$. subterraneus, $M$. liechtensteini having an anterior part between that of $M$. multiplex and $M$. subterraneus. The pitymyan rhombus is significantly less inclined in $M$. multiplex than in $M$. subterraneus and $M$. liechtensteini. The

Table 1. Description, analysis of variance and Scheffé's test of the total length (TL), the anterior part (AP), the inclination of the pitymyan rhombus $(\mathrm{PR})$ and the close of the anterior loop $(\mathrm{AL})$ of the first lower molar in Microtus subterraneus (M. s.), M. multiplex (M. m.) and M. liechtensteini (M. l.). Units for TL, PR and AL are $10^{-2} \mathrm{~mm}, \mathrm{AP}$ is without unity. $\mathrm{SD}$ - standard deviation. * Means with the same letter are not significantly different.

\begin{tabular}{|c|c|c|c|c|c|}
\hline Variable & Species & $n$ & Mean & SD & $\begin{array}{l}\text { Scheffé's test } \\
(p<0.05)^{*}\end{array}$ \\
\hline TL & $\begin{array}{l}M . s . \\
M . m . \\
M . l .\end{array}$ & $\begin{array}{r}226 \\
166 \\
156 \\
\text { nalysis }\end{array}$ & $\begin{array}{r}249.0 \\
259.9 \\
270.1 \\
\text { iance: } p\end{array}$ & $\begin{array}{r}9.9 \\
21.3 \\
14.8 \\
1\end{array}$ & $\begin{array}{l}\text { A } \\
\text { B } \\
\text { C }\end{array}$ \\
\hline $\mathrm{AP}$ & $\begin{array}{l}M . s . \\
M . m . \\
M . l .\end{array}$ & $\begin{array}{r}226 \\
166 \\
156 \\
\text { nalysis }\end{array}$ & $\begin{array}{r}0.524 \\
0.518 \\
0.521 \\
\text { iance: } p\end{array}$ & $\begin{array}{r}0.013 \\
0.017 \\
2^{0.017}\end{array}$ & $\begin{array}{c}\text { A } \\
\text { B } \\
\text { A B }\end{array}$ \\
\hline PR & $\begin{array}{l}M . s . \\
M . m . \\
M . l .\end{array}$ & $\begin{array}{r}226 \\
166 \\
156 \\
\text { nalysis }\end{array}$ & $\begin{array}{r}-0.7 \\
3.5 \\
-0.5 \\
\text { iance: } p\end{array}$ & $\begin{array}{r}3.5 \\
4.6 \\
3.8 \\
1\end{array}$ & $\begin{array}{l}\text { A } \\
\text { B } \\
\text { A }\end{array}$ \\
\hline $\mathrm{AL}$ & $\begin{array}{l}M . s . \\
M . m . \\
M . l .\end{array}$ & $\begin{array}{r}226 \\
166 \\
156 \\
\text { nalysis }\end{array}$ & $\begin{array}{c}15.5 \\
22.9 \\
24.1 \\
\text { iance: } p\end{array}$ & $\begin{array}{r}6.1 \\
8.6 \\
9.7 \\
1\end{array}$ & $\begin{array}{l}\text { A } \\
\text { B } \\
\text { B }\end{array}$ \\
\hline
\end{tabular}


Table 2. Description, analysis of variance and Scheffés test of the total length (TL), the anterior part (AP), the inclination of the pitymyan rhombus (PR) and the close of the anterior loop (AL) of the first lower molar in the three groups of Microtus liechtensteini. Units for TL, PR and AL are $10^{-2} \mathrm{~mm}, \mathrm{AP}$ is without unity. SD - standard deviation. * Means with the same letter are not significantly different.

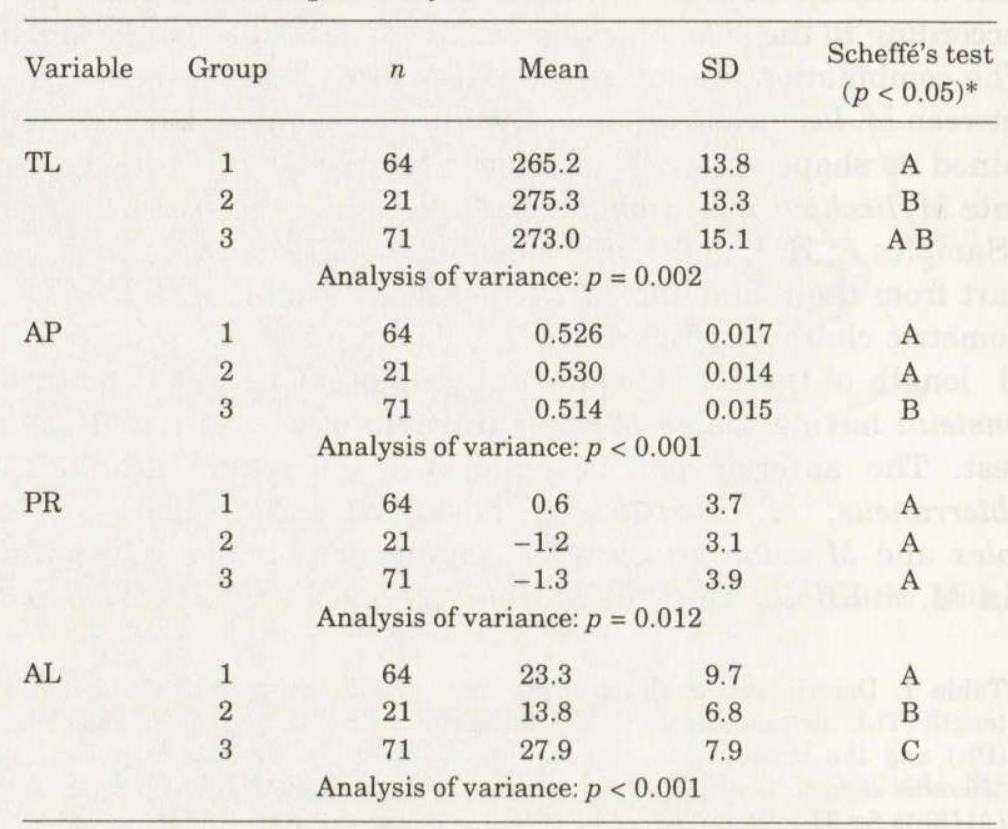

anterior loop is evidently more closed in $M$. subterraneus than in $M$. multiplex and $M$. liechtensteini.

Projection of centroids of ten $M$. liechtensteini samples on to the first two canonical axes (51\% and $19 \%$ respectively of variance between classes) revealed the existence of three sample groups (Fig. 4): group 1: samples B to G, group 2: sample A, group 3: samples H, I, and J. Group 3 was discriminated from groups 1 and 2 by the first canonical axis, while axis 2 separated groups 1 and 2 . The first canonical axis was significantly positively correlated $(p<0.05)$ with variables measure $16(0.74)$, measure $5(0.61)$, measure $20(0.58)$ and measure $22(0.57)$. The second axis had significant positive correlations $(p<0.05)$ with variables measure $18(0.71)$, measure $1(0.50)$, measure $8(0.48)$ and measure $17(0.47)$.

Morphometric characteristics are given in Table 2. The total length of the $\mathrm{M}_{1}$ is significantly greater in group 2 than in group 1, while group 3 was intermediate between groups 1 and 2 . The anterior part is significantly shorter in group 3 than in the other two groups. None of the three groups differs significantly from the others with regard to the tilt of the inclination of the pitymyan rhombus. However, combined groups 2 and 3 are significantly different $(p<0.05)$ from group 1 with a less inclined pitymyan rhombus. The anterior loop is significantly different 
between the 3 groups, group 2 having the most closed anterior loop and group 3 the least closed.

\section{Discussion and conclusion}

General morphological analysis of 31 samples of $M$. subterraneus, M. liechtensteini and $M$. multiplex confirmed the close kinship between $M$. liechtensteini and $M$. multiplex compared with $M$. subterraneus. This is in accordance with taxonomic arrangement of these species (Niethammer and Krapp 1982). M. liechtensteini is characterized by a long $\mathrm{M}_{1}$. Its pitymyan rhombus, which is more tilted than in $M$. multiplex suggesting to be more evolved than $M$. multiplex (Brunet-Lecomte 1988, 1990).

Among $M$. liechtensteini, samples B to G were morphologically closer to $M$. multiplex, than samples A, H, I, and J. The independent position of samples A, $\mathrm{H}, \mathrm{I}$, and $\mathrm{J}$ was confirmed also by the discriminant analysis of ten $M$. liechtensteini samples. The distribution pattern of the three groups recognized (Fig. 4) corresponds well with main plant communities. Group 1 with the medio-European morphotype of $\mathrm{M}_{1}$ is limited to the continental zone. Group 2, which is also characterized by a medio-European morphotype, populates the sub-Mediterranean zone but close to the continental zone. Group 3, which is of medio-European type with marked Mediterranean morphotype trends, originate from the sub-Mediterranean zone.

Group 1 includes also topotypes of $M$. l. liechtensteini, so it should be ascribed to the nominate subspecies. Group 2, which originates from the type locality of $M$. l. petrovi, is ascribed to that subspecies. Taxonomic position of group 3 is left open, also because of lack of other (e.g. karyological) data.

The following hypothetical evolution of $M$. liechtensteini and the three above recognized groups is suggested: $M$. liechtensteini derived directly from $M$. multiplex or from a common ancestor with $M$. multiplex, by cladogenesis during the upper Pleistocene in a region that favoured the isolation of populations (in glacial refuge). Next, group 2 (petrovi) evolved from group 1 (liechtensteini) in a region on the boundary of continental and the sub-Mediterranean zones. Either group 1 or 2 evolved into group 3 in the sub-Mediterranean zone. But it should be stressed that there are great differences in shape between groups 2 and 3 although they are both located in the same biogeographic region and are close in terms of distance. Therefore we cannot exclude the possibility that the group 3 does not belong to $M$. liechtensteini, and had evolved from a different lineage that $M$. liechtensteini / M. multiplex. If we accept that chromosome divergence preceedes morphological divergence, a considerable chromosome differences should be also expected between groups 2 and 3.

Acknowledgements: We thank L. Lipej (MS, Institute of Biology, Piran) for loan of material from owl pellets. 


\section{References}

Brunet-Lecomte P. 1988. Les campagnols souterrains (Terricola, Arvicolidae, Rodentia) actuels et fossiles d'Europe occidentale. $\mathrm{Ph}$. D. thesis, Université de Bourgogne: $1-146$.

Brunet-Lecomte P. 1990. Evolution morphologique de la première molaire inférieure des campagnols souterrains d'Europe (Arvicolidae, Rodentia). Z. Säugetierk. 55: 371 - 382

Corbet G. B. 1978. The Mammals of Palearctic region: a taxonomic review. British Museum (Nat. Hist.). Cornell Univ. press, London: $1-314$.

Djulić B. and Mirić D. 1967. Catalogus Faunae Jugoslaviae, IV/4 Mammalia. Academia Scientarum et Artium Slovenica, Ljubljana: $1-45$.

Ellerman J. R. and Morrison-Scott T. C. S. 1951. Checklist of Palearctic and Indian mammals, 1758 to 1946. British Museum (Nat. Hist.): $1-810$.

Graf J. D. and Meylan A. 1980. Polymorphisme chromosomique et biochimique chez Pitymys multiplex (Mammalia, Rodentia). Z. Säugetierk. 45: 133 - 148.

Jovanović B., Jovanović R. and Zupančič M., eds 1986. Natural potential vegetation of Yugoslavia. Sci. Council of vegetation map of Yugoslavia, Ljubljana: $1-122$.

Král B., Zima J. and Herzig-Straschil B. 1978. Karyotype analysis of voles of the genus Pitymys from southern Austria. Folia zool. 27: 129 - 133.

Kryštufek B. 1983. New subspecies of Pitymys liechtensteini Wettstein, 1927 from Yugoslavia. Biol. vestn., Ljubljana 31: $73-82$.

Kryštufek B. 1984. Pitymys liechtensteini Wettstein, 1927 (Rodentia, Mammalia) new species in fauna in the Socialist Republic of Bosnia and Herzegovina. Glasnik Zemaljskog muzeja Bosne i Herzebovine, Prirodne nauke, N. S. 23: $191-194$.

Lipej J. 1988. [Feeding ecology of four owl species in Slovene Istria.] B. Sc. thesis, Ljubljana: 1 - 60. [In Slovene]

Meylan A. 1970. Caryotypes et distribution de quelques Pitymys européens (Mammalia, Rodentia). Revue suisse Zool. 77: 562 - 575 .

Niethammer J. and Krapp K. 1982. Handbuch de Säugetiere Europas, Band 2/l. Akademische Verlagsgellschaft, Wiesbaden: $1-649$.

Nowak R. M. 1991. Walker's mammals of the World. Fifth ed. The John Hopkins Univ. Press, London: $1-1629$

Petrov B. 1992. Mammals of Yugoslavia, insectivores and rodents. Nat. Hist. Mus. Belgrade, Suppl. 37: $1-186$.

Petrov B. and Zivković S. 1971. On Pitymys liechtensteini Wettstein, 1927 (Rodentia, Mammalia) in Yugoslavia. Arhiv bioloških nauka, Beograd 23: $31-32$.

Petrov B. and Zivković S. 1979. Present knowledge on the systematics and distribution of Pitymys (Rodentia, Mammalia) in Yugoslavia. Biosistematika, Beograd 5: $113-125$.

Purger J. J. and Karanović T. 1991. First data on small mammal fauna from Krnjeuša (Bosanska Krajina), as obtained by a barn owl, Tyto alba (Scop., 1769) pellet analysis. Biol. vestnik, Ljubljana 39: $41-44$.

Storch G. and Winking H. 1977. Zur Systematik der Pitymys multiplex-Pitymys liechtensteini gruppe (Mammalia, Rodentia). Z. Säugetierk. 42: $78-88$.

Sugar J. 1984. A niew view of the plant cover and phytogeographical zonation of Istria. Acta Bot. Croatica, Zagreb 43: $225-234$.

Tvrtković N., Djulić B. and Kruštufek B. 1979. Methods of distinction of Pitymys liechtensteini Wettstein, 1927 and Pitymys subterraneus De Sélys-Longchamps, 1836 and their distribution in northwestern Yugoslavia. Biosistematika, Beograd 5: 201 - 214.

Zivković S., Petrov B. and Rimsa D. 1975. New data on the taxonomy of Balkan Pitymys representatives (Mammalia, Rodentia) in the light of karyological analysis. Biosistematika, Beograd 1: $31-42$.

Received 15 February 1993, accepted 3 June 1993. 